D) Check for updates

Cite this: Analyst, 2021, 146, 882

\title{
Lithium-7 qNMR as a method to quantify lithium content in brines using benchtop NMR†
}

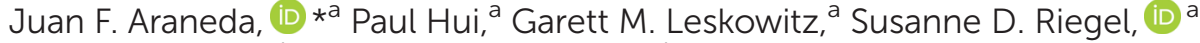 \\ Rodrigo Mercado ${ }^{b}$ and Christopher Green ${ }^{b}$
}

\begin{abstract}
A novel ${ }^{7} \mathrm{Li}$ quantitative NMR (qNMR) method to analyze lithium was developed to determine the lithium content in real brine samples using benchtop NMR instruments. The method was validated, and limits of detection and quantification of 40 and 100 ppm, respectively, were determined. Linearity, precision, and bias were also experimentally determined, and the results are presented herein. The results were compared to those obtained using atomic absorption (AA) spectroscopy, currently one of the few validated methods for the quantification of lithium. The method provides both accurate and precise results, as well as excellent correlation with AA. The absence of matrix effects, combined with no need for sample preparation or deuterated solvents, shows potential applicability in the mining industry.
\end{abstract}

Received 22nd October 2020 Accepted 18th November 2020 DOI: 10.1039/d0an02088e rsc.li/analyst

\section{Introduction}

Lithium is used in many industrial manufacturing processes such as glass, ceramics, lubricating grease, and pharmaceuticals. ${ }^{1-4}$ However, its importance in the last two decades has increased due in part to the superior performance of lithium-ion batteries, ${ }^{5-7}$ which are widely used in a variety of electronic devices, such as notebooks, cellphones, cameras, etc. ${ }^{8}$ The rising demand for electric vehicles is projected to significantly increase the need for lithium in the coming years. ${ }^{9,10}$ This demand is expected to grow up to 900 ktons per year by 2025, which is approximately three times higher than in $2018 .^{7}$

Lithium is mainly sourced from either spodumene or brine, with the latter consisting of $59 \%$ of the market share. ${ }^{11,12}$ Lithium-containing brines are concentrated by solar evaporation in multiple stages and are monitored quantitatively at each step until the lithium content reaches approximately $6 \% .^{13-15}$ The most common techniques for this quantification are atomic absorption (AA) and inductively coupled plasma (ICP) spectroscopy. However, both methods require significant sample manipulation and are prone to interference caused by

\footnotetext{
${ }^{a}$ Nanalysis Corp., 1-4600 5 St NE, Calgary, AB, T2E 7C3, Canada. E-mail: juan.araneda@nanalysis.com

${ }^{b}$ Sociedad Quimica y Minera de Chile S.A (SQM), Laboratorio de Desarrollos Analiticos Av. Balmaceda 3228, Antofagasta, Chile

$\dagger$ Electronic supplementary information (ESI) available: Table S1, $T_{1}$ measurements; Table S2, intra- and inter-day precision; Table S3, precision and bias by NMR; Table S4, calibration curves; Table S5, residual outputs; regression analysis comparing results from NMR and AA (PDF). See DOI: 10.1039/d0an02088e
}

other ions present in solution, representing a significant matrix effect. ${ }^{16-19}$

Nuclear magnetic resonance (NMR) spectroscopy has become one of the most valuable tools a chemist has, partly due to its extraordinary ability for structural elucidation. ${ }^{20-24}$ By understanding the fundamental concepts of NMR spectroscopy (i.e., coupling constant, chemical shift, and integration), scientists can take advantage of this technique to gain insight into the different atoms present in a molecule, such as how they are connected and their relative spatial proximities. $^{25,26}$ More recently, NMR spectroscopy has also been applied to quantitative applications (qNMR), particularly in the areas of natural products and medicinal chemistry, because it is non-destructive and inherently quantitative in nature. ${ }^{27-34}$ However, qNMR spectroscopy is not as widely used in industry as other techniques such as UV-Vis, GC-MS, ICP, AA and IR spectroscopy due to the cost and size associated with traditional high-field instruments.

Oftentimes, qNMR applications make use of nuclei with spin $I=\frac{1}{2}\left(e . g .,{ }^{1} \mathrm{H},{ }^{19} \mathrm{~F},{ }^{31} \mathrm{P}\right)$ rather than quadrupolar nuclei, which have spin $I>\frac{1}{2}\left(e . g .,{ }^{7} \mathrm{Li},{ }^{11} \mathrm{~B},{ }^{23} \mathrm{Na},{ }^{27} \mathrm{Al}\right)$. The quadrupole moment associated with these nuclei represents an asymmetry in charge distribution, and its interaction with local fluctuating electric field gradients, provided by electrons and other moving charges, represents a relaxation mechanism. This interaction helps to explain the fact that quadrupolar nuclei usually give rise to broader signals than spin-1/2 nuclei. These broad signals can be problematic to qNMR applications, since the signal will be spread out over a larger frequency range, effectively reducing the signal intensity and consequently the signal-to-noise ratio (SNR). ${ }^{35}$ There are, however, a few reported applications that use quadrupolar nuclei in 
qNMR. $^{36-38}$ For example, in 2018 Fernandez and coworkers reported the quantitative analysis of boric acid in biocides using ${ }^{11} \mathrm{~B}$ qNMR. ${ }^{39}$ However, to the best of our knowledge there are no reports of lithium NMR in quantitative applications.

In the last few years, the emergence of benchtop NMR spectrometers that are affordable, portable, and require minimal maintenance has accelerated the introduction of this technique in industrial settings. ${ }^{40-44}$ This is reflected by the increasing number of publications incorporating benchtop NMR instruments in a variety of industrial applications such as quality control, quality assurance, and process analytical technology (PAT) ${ }^{45-48}$ Due to the important role of lithium in the future global energy demand, we decided to explore the potential of benchtop NMR instruments in the quantification of this metal in brines. In this article, we present our findings in the direct quantification of lithium without any additional sample preparation, dilution, or need for deuterated solvents.

\section{Experimental section}

\section{Brine samples}

For this study, 16 samples taken from underground brine and evaporation ponds at SQM site at Salar de Atacama, near Antofagasta in northern Chile, were used. Samples were divided in two sets. One set from each brine was sent to Nanalysis Corp. in Calgary, Canada to be analyzed by NMR spectroscopy, and the other set remained at the SQM facilities in Chile to be analyzed by AA.

Following collection, some samples with high lithium content presented crystallization of some of the salts after a few days, which happened during shipment from chile to Canada. These samples were transferred to a flask, weighed, and heated to $60^{\circ} \mathrm{C}$ for 1 hour. Distilled water was added until all the solids were dissolved. Samples were allowed to reach room temperature, and the weight was adjusted by evaporation of excess water or addition of distilled water until the initial weight was reached. Note that heating of the samples is not required for on-site analysis where shipment or storage of the samples is unnecessary, as the samples can be transferred to an NMR tube and analyzed directly, provided that this is done in the few days prior to the appearance of precipitate.

\section{Instrumentation}

All ${ }^{7} \mathrm{Li}$ NMR spectra were obtained at $32{ }^{\circ} \mathrm{C}$ using a Nanalysis 60PRO benchtop NMR spectrometer at a $23.46 \mathrm{MHz}$ lithium frequency (1.418 tesla). The qNMR experiments were performed with the following optimized parameters: spectral width, 50 ppm; spectral center, 0 ppm; number of complexvalued points, 4096; scans, 4; interscan delay, 115 seconds; pulse angle, $90^{\circ}$ (as determined by nutation); ${ }^{49}$ acquisition time, 3.44 seconds. All NMR measurements were carried out with a fixed receiver gain of $35 \mathrm{~dB}$ to ensure consistency of quantitative results and to avoid receiver saturation. All experiments were conducted without any form of decoupling. NMR spectra were acquired without deuterated solvents, and samples were used as received without any additional preparation. Lithium chemical shift is provided relative to aqueous LiCl $3 \mathrm{M}$ (0 ppm). A line-broadening factor of $1.0 \mathrm{~Hz}$ was applied to the free induction decays (FID) prior to Fourier transformation. ${ }^{7} \mathrm{Li}$ NMR spectra were manually corrected for phase and baseline distortions using MestReNova software (v14.1.0). The region of integration was constant between samples (+3 to $-3 \mathrm{ppm})$. Microsoft Excel was used for data analysis. To improve and monitor precision, each measurement was performed in triplicate.

AA analysis was performed using a Thermo Elemental S4 system from Thermo Scientific running SOLAAR Data Station 11.0 software. The atomic line for $\mathrm{Li}$ at $670.8 \mathrm{~nm}$ was monitored with a $0.5 \mathrm{~mm}$ slit. The air/acetylene flow rate was maintained at $1.0 \mathrm{~mL}$ per minute. The instrument is equipped with a $50 \mathrm{~mm}$ burner at $\sim 45^{\circ}$. A sample aspiration rate of $7 \mathrm{~mL}$ per minute was used. The AA methodology used is in agreement with the Chilean Standard Method NCh3349/2020 for the analysis of brines and ASTM D3561-16. The method used five standards for the calibration curve with relative standard deviations below $2 \%$ and residuals below 2\%. Microsoft Excel was used for data analysis.

\section{Results and discussion}

\section{Optimization of qNMR method}

Lithium has two NMR active nuclei, ${ }^{6} \mathrm{Li}$ and ${ }^{7} \mathrm{Li}$, with natural abundances of 7.6 and $92.4 \%$ and gyromagnetic ratios of $3.9371 \times 10^{7}$ and $10.398 \times 10^{7} \mathrm{rad} \mathrm{s}^{-1} \mathrm{~T}^{-1}$, respectively. The spin quantum numbers are 1 for ${ }^{6} \mathrm{Li}$ and $3 / 2$ for ${ }^{7} \mathrm{Li}$. Due to its greater sensitivity, lithium-7 is the most used isotope in lithium NMR spectroscopy. ${ }^{50-52}$

NMR is inherently quantitative and in most qNMR applications a standard (or calibrant) of known concentration is added to compare its relative integration with that of the compound of interest. ${ }^{31}$ In aqueous solution, the lithium ions are solvated with labile $\mathrm{H}_{2} \mathrm{O}$ ligands, which form a hydration shell. ${ }^{53,54}$ The ${ }^{7} \mathrm{Li}$ NMR signal is therefore in a dynamic exchange regime that is fast on the NMR timescale, yielding a single resonance. The lithium content is accordingly determined as a total lithium composition, independent of the nature of the species (e.g., $\mathrm{Li}_{2} \mathrm{CO}_{3}, \mathrm{LiCl}, \mathrm{Li}_{2} \mathrm{SO}_{4}$, etc.). This makes the use of an internal calibrant impractical and as a result, a calibration curve correlating the known concentration of the analyte and its signal response was used. The calibration curve was recorded by preparing several solutions of $\mathrm{LiCl}$ in $\mathrm{H}_{2} \mathrm{O}$ at concentrations of $0.25,0.50,1,3,7.5,15$ and $30 \%$ (w/w\%).

The first step in developing a ${ }^{7}$ Li-NMR method to quantify lithium content involved the determination of the optimal acquisition parameters. Most of these can be extracted from literature (e.g., number of points, digital resolution, and pulse angle). However, the most crucial parameter for accurate quantification is the recycle time (i.e., interscan delay + acqui- 
sition time) between scans. It is generally agreed upon that for qNMR, an interscan delay of 5 to 7 times the longitudinal relaxation time $T_{1}$ should be used to ensure that more than $99 \%$ of the equilibrium magnetization has been recovered
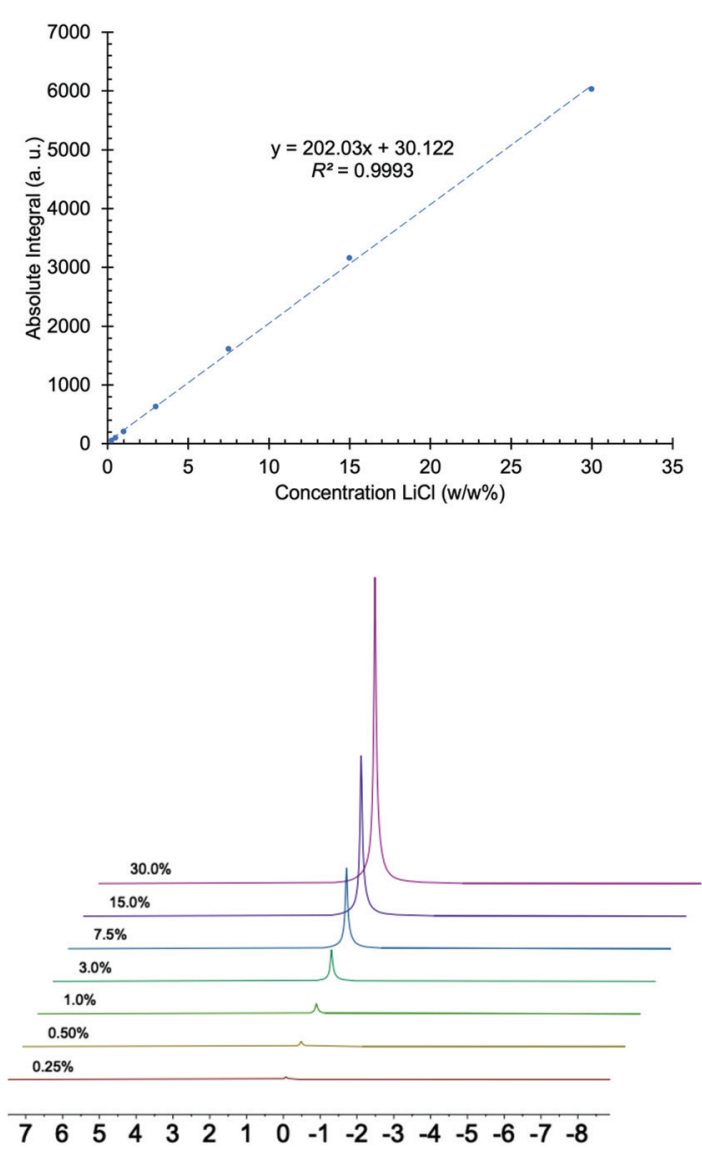

Fig. 1 Top: graph of absolute integral versus concentration of $\mathrm{LiCl}$ made with $0.25,0.50,1,3,7.5,15$ and $30(\mathrm{w} / \mathrm{w} \%)$ solutions. Bottom: ${ }^{7} \mathrm{Li}$ NMR spectra of $\mathrm{LiCl}$ solutions used to produce the graph. before the next scan is acquired. ${ }^{26}$ Table S1† shows the $T_{1}$ values of several $\mathrm{LiCl}$ solutions at different concentrations along with the $T_{1}$ of four randomly selected brine samples. The $T_{1}$ values of the solutions prepared in the lab range from 3.7 to 23.2 seconds and the values for the brine samples are on the order of 13 seconds.

\section{Method validation}

To ensure the proposed method was effective for the intended application, it was validated using samples prepared in the lab, reference standard materials, and lithium samples from brine pools. Linearity, intra-day and inter-day precision, limit of detection (LOD), limit of quantification (LOQ), and bias were evaluated. ${ }^{55-58}$

The linear response of the instrument was determined by preparing $\mathrm{LiCl}$ solutions in $\mathrm{H}_{2} \mathrm{O}$ at concentrations of 0.25 , $0.50,1,3,7.5,15$ and $30 \%(\mathrm{w} / \mathrm{w})$ and plotting the absolute integration area versus concentration. Fig. 1 shows that the instrument's response is linear over this range of percent composition, with a coefficient of determination $\left(R^{2}\right)$ of 0.9993 .

Brine samples contain several ions and elements in addition to lithium. Some of the most common species are sodium, potassium, boron, magnesium, calcium, chloride, and sulfate (Table 1). In some cases, the amount of such species in solution can be significantly higher than lithium itself. While such species in principle exhibit no absorption peaks in the ${ }^{7} \mathrm{Li}$ NMR spectrum, in practice, small auxiliary effects attributable to these species may introduce complications in the instrument's response. Most notably, it's known that ionic strength (i.e., salt concentration of the samples) can affect $T_{1}$ relaxation values, and variable salt concentrations can affect the tuning and matching of probes in high-field instruments. ${ }^{59,60}$ For these reasons, the matrix effect was investigated by comparing the slope of a calibration curve prepared using pure water with the slopes of two brine samples prepared using the standard addition method. The slope ratio

Table 1 Partial ionic composition of brine samples used in this study

\begin{tabular}{|c|c|c|c|c|c|c|c|}
\hline Sample & $\mathrm{Li}^{a}(\mathrm{w} / \mathrm{w} \%)$ & $\mathrm{K}^{b}(\mathrm{w} / \mathrm{w} \%)$ & $\mathrm{Na}^{b}(\mathrm{w} / \mathrm{w} \%)$ & $\left.\mathrm{SO}_{4}{ }^{b} \mathrm{~W} / \mathrm{W} \%\right)$ & $\mathrm{Cl}^{c}(\mathrm{w} / \mathrm{w} \%)$ & $\mathrm{B}^{b}(\mathrm{w} / \mathrm{w} \%)$ & $\operatorname{TDS}^{d}\left(\mathrm{~g} \mathrm{~L}^{-1}\right)$ \\
\hline 1 & 0.163 & 2.25 & 6.76 & 0.23 & 16.14 & 0.04 & 268 \\
\hline 2 & 0.197 & 2.54 & 6.39 & 1.35 & 15.74 & 0.06 & 276 \\
\hline 3 & 0.226 & 2.36 & 5.53 & 0.12 & 16.68 & 0.05 & 269 \\
\hline 4 & 0.289 & 3.34 & 4.63 & 0.36 & 16.89 & 0.07 & 276 \\
\hline 5 & 0.339 & 3.13 & 4.1 & 0.66 & 17 & 0.09 & 277 \\
\hline 6 & 0.439 & 3.16 & 4.47 & 5.83 & 17.39 & 0.11 & 347 \\
\hline 7 & 0.471 & 2.02 & 4.52 & 1.75 & 15.86 & 0.08 & 269 \\
\hline 8 & 0.598 & 2.22 & 2.22 & 2.5 & 17.1 & 0.18 & 284 \\
\hline 9 & 0.654 & 1.79 & 1.82 & 0.19 & 18.45 & 0.06 & 268 \\
\hline 10 & 0.755 & 1.9 & 1.31 & 4.89 & 17.75 & 0.26 & 317 \\
\hline 11 & 0.802 & 1.55 & 0.75 & 1.5 & 20.98 & 0.22 & 311 \\
\hline 12 & 1.060 & 0.45 & 0.44 & 1.04 & 21.66 & 0.27 & 306 \\
\hline 13 & 1.969 & 0.08 & 0.2 & 0.22 & 26.36 & 0.27 & 345 \\
\hline 14 & 5.032 & 0.05 & 0.06 & 0.04 & 32.12 & 0.75 & 408 \\
\hline 15 & 6.243 & 0.17 & 0.07 & 0.04 & 34.91 & 0.75 & 434 \\
\hline 16 & 6.144 & 0.06 & 0.07 & 0.04 & 35.09 & 0.91 & 436 \\
\hline
\end{tabular}

${ }^{a}$ Determined by AA. ${ }^{b}$ Determined by ICP-OES. ${ }^{c}$ Determined by titration (Mohr's method). ${ }^{d}$ Total dissolved solids (TDS) is a measure of the total ionic concentration of dissolved minerals in water (salinity). 
(slope of standard addition/slope of pure sample) of 0.964 and 0.956 for the two brine samples suggests that, over the broad range of concentrations used, matrix effects should induce less than a few percent error in linear estimates of concentration (Fig. 2).

Nutation experiments are commonly used in NMR spectroscopy to calibrate the $90^{\circ}$ pulse angle. ${ }^{49}$ If samples of high ionic strength affected the instrument's response, it would be evidenced by different results in the nutation experiments. A potential effect might be a decrease in the $\mathrm{Q}$ factor of the radio-frequency resonant detection circuit due to dielectric dissipation in the aqueous sample when the ionic strength of the solution is high. ${ }^{61}$ This could be expected to reduce the effective signal strength at high lithium concentrations or high concentrations of other ions. A significantly reduced $\mathrm{Q}$ factor will also cause the nutation rate to decrease, and so saltier samples should exhibit longer $90^{\circ}$ nutation times. Table 2 shows very similar nutation values for samples containing different lithium chloride content ( 1 to $30 \mathrm{w} / \mathrm{w} \%$ ) and more ions in solution (samples 11 and 14). There is a monotonic trend in nutation times, but the nutation rate varies by only about $1.1 \%$ over the whole range of concentrations that was studied. While this is small compared to the level of precision observed in the concentration estimates herein (see below), an analysis with higher-precision measurements and sample-

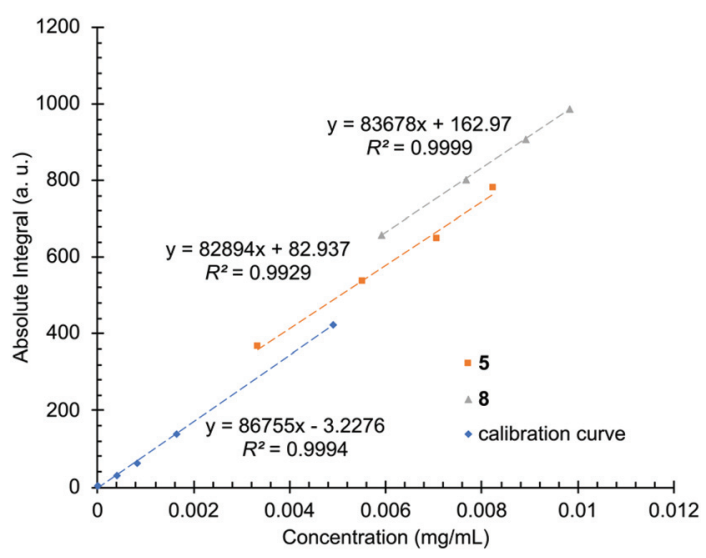

Fig. 2 Calibration curves recorded with solutions of lithium chloride and distilled water (blue) and by spiking two brine samples (5 in orange and 8 in grey) with known amounts of lithium.

Table 2 Nutation experiments carried out using solutions containing a different $\mathrm{LiCl}$ content (1 to $30 \mathrm{w} / \mathrm{w} \%$ ) and real samples from brine pools (samples 11 and 14)

\begin{tabular}{ll}
\hline Sample & $90^{\circ}$ Nutation $(\mu \mathrm{s})$ \\
\hline 11 & 24.17 \\
14 & 24.07 \\
$30 \%$ & 24.25 \\
$15 \%$ & 24.22 \\
$3 \%$ & 24.03 \\
$1 \%$ & 23.98
\end{tabular}

preparation methods should take this into account. The small variation in nutation rates (and the attendant signal amplification factors) should have a minimal effect on the accuracy and precision of the results presented herein.

The precision (repeatability) of the instrument was evaluated by performing intra- and inter-day experiments. Intra-day precision was evaluated by running a sample of LiCl (15 $\mathrm{w} / \mathrm{w} \%$ ) in triplicate, and inter-day precision was studied by analyzing the same sample in triplicate for six consecutive days. In both cases, the absolute integration area was monitored (see ESI, Table S2 $\dagger$ ) and the relative standard deviations ranged from 0.03 to $0.30 \%$. Precision and bias were also evaluated following the American Public Health Association (APHA) 1040 B guide for method development and evaluation. A certified standard solution of lithium carbonate for ICP containing $1002 \mathrm{mg} \mathrm{L}^{-1} \pm 8 \mathrm{mg} \mathrm{L}^{-1}$ lithium was analyzed in 10 replicates. The standard deviation was determined to be $11 \mathrm{mg} \mathrm{L}^{-1}$ and the bias was $-1 \mathrm{mg} \mathrm{L}^{-1}$.

Limit of detection (LOD) and limit of quantification (LOQ) are important validation parameters relevant for identifying and quantifying an analyte. For the lithium NMR studies the detection limit was established as the lowest concentration of $\mathrm{Li}^{+}$that gave rise to a signal intensity for which the SNR equals 3 and the LOQ as the lowest concentration that gives a signal with an SNR of 10 . In this method, the LOD was determined to be $40 \mathrm{ppm} \mathrm{Li}^{+}$, and the LOQ was determined to be $100 \mathrm{ppm}$ $\mathrm{Li}^{+}$. It should be noted that LOQ is the concentration of analyte for which the signal of interest generates the minimal required SNR for the given method precision and different applications may require a higher SNR for LOQ.

\section{Sample analysis}

The linearity study showed in Fig. 1 displays an excellent linear correlation with an $R^{2}$ value of 0.9993 . However, to use a specific calibration curve, the validity of the linear regression model should also be evaluated. ${ }^{58,62}$ One of the simplest ways to evaluate a regression analysis is to examine the residual errors. If the regression model is valid, then the residual errors should be randomly distributed about an average residual error of zero. The calibration curve ranging from 0.25 to 30 (w/w\%) LiCl showed excellent linear regression, but the residual error was larger for samples at low concentrations. For that reason, the calibration curve was split into two smaller ones, one ranging from 0.25 to 3 and the other from 3 to $30(\mathrm{w} / \mathrm{w} \%)$ LiCl. Samples were initially analyzed with the full calibration curve to estimate the lithium content and subsequently with the corresponding linear regression model to accurately determine the lithium content.

The method was used to analyze real samples taken from brines and evaporation ponds and the results are shown in Table 3. The samples were analyzed by NMR directly from the brine pools, no sample preparation or dilution was performed. Samples were analyzed in triplicate, and in all cases, the relative standard deviation (RSD) values were below $2 \%$. To evaluate the reliability of the NMR results, the samples were also analyzed by AA. The results show excellent correlation, with 
Table 3 Lithium content by ${ }^{7} \mathrm{Li} \mathrm{qNMR}$ and AA in brine samples. All concentrations are expressed as $\mathrm{w} / \mathrm{w} \%$ lithium

\begin{tabular}{lllll}
\hline Sample & Li content by NMR & RSD $^{a}$ & Li content by AA & Diff. $^{b}(\%)$ \\
\hline 1 & 0.166 & 1.86 & 0.163 & 1.8 \\
2 & 0.201 & 1.06 & 0.197 & 2.0 \\
3 & 0.222 & 0.83 & 0.226 & -1.8 \\
4 & 0.292 & 1.56 & 0.289 & 1.0 \\
5 & 0.349 & 0.70 & 0.339 & 2.9 \\
6 & 0.467 & 0.68 & 0.439 & 6.4 \\
7 & 0.478 & 0.34 & 0.471 & 1.5 \\
8 & 0.617 & 0.23 & 0.599 & 3.0 \\
9 & 0.684 & 0.46 & 0.654 & 4.6 \\
10 & 0.811 & 0.51 & 0.755 & 7.4 \\
11 & 0.850 & 0.55 & 0.802 & 6.0 \\
12 & 1.136 & 0.27 & 1.060 & 7.2 \\
13 & 2.110 & 0.13 & 1.969 & 7.2 \\
14 & 5.271 & 0.06 & 5.032 & 4.7 \\
15 & 6.380 & 0.11 & 6.243 & 2.2 \\
16 & 6.480 & 0.04 & 6.144 & 5.5
\end{tabular}

${ }^{a}$ Relative standard deviation of NMR measurements. ${ }^{b}$ ((Li content by NMR - Li content by AA)/(Li content by AA $)) \times 100$.

most of the results showing differences below $5 \%$. The fact that the inter-day precision studies show excellent stability suggests that multiple recalibrations are not necessary with the NMR method, unlike AA.

One common approach to compare two analytical methods is the use of a regression line. In this approach, the results of the two methods are plotted on the two axes of a regression graph, with each point on the graph representing a single sample measured by the two analytical techniques being compared. In an ideal situation, if both techniques yield identical results, the regression line will have a slope of 1 and 0 intercept. However, in practice this almost never occurs and some deviation from the ideal results is inevitable. ${ }^{58}$ The NMR results were plotted on the $y$-axis and the AA data on the $x$-axis of Fig. 3. The intercept obtained is 0.0065 , with the upper and lower confidence limits of 0.0366 and -0.0236 . The slope of

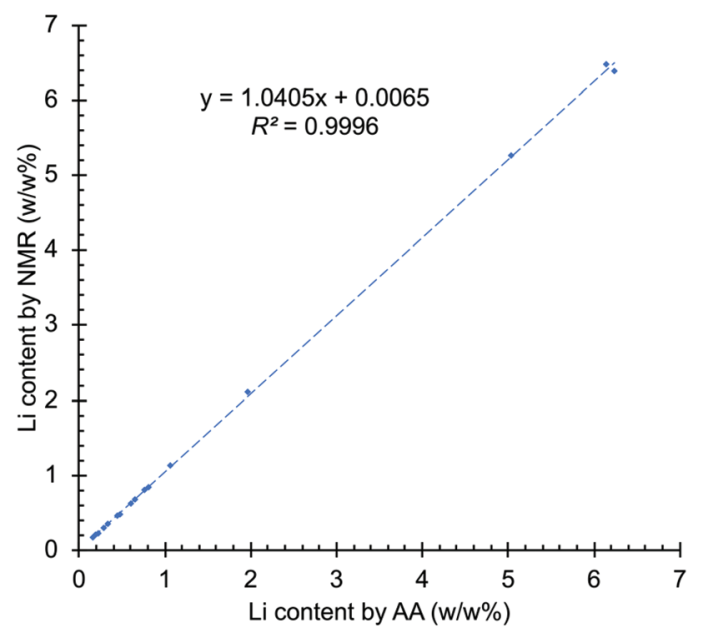

Fig. 3 Graph of regression line analysis comparing results from NMR and $\mathrm{AA}$. the graph is 1.0405 , with the $95 \%$ confidence interval of 1.029-1.052 and the coefficient of determination $\left(R^{2}\right)$ is equal to 0.9996 (see ESI $\dagger$ for a detailed explanation). The results show that the confidence interval of the intercept contains the 0 value and the intercept is only slightly off the unit slope, demonstrating the high correlation between both techniques. NMR slightly overestimated the concentration of lithium at high concentrations, as reflected in the slope of Fig. 3, but the results are within the accepted values for the intended application.

One of the major drawbacks of NMR spectroscopy as an analytical technique to quantify components is the lower sensitivity compared to other techniques such as ICP and AA. ${ }^{63,64}$ For example, in this particular application the LOD and LOQ experimentally determined by AA for lithium are 0.06 and $0.17 \mathrm{ppm}$, respectively. These values are significantly lower than the ones determined by low-field NMR (LOD was determined to be $40 \mathrm{ppm}$ and the LOQ $100 \mathrm{ppm} \mathrm{Li}{ }^{+}$). However, the method reported herein provides more than sufficient sensitivity to quantify the lithium content in real brine pool samples. The superior sensitivity of AA does not offer any particular benefit for this application.

\section{Conclusions}

A new method to determine lithium content in brine pools has been developed. Although traditional methods used in the lithium mining industry (e.g., ICP and AA) provide lower LOQ and LOD than NMR spectroscopy, the method reported herein provides more than sufficient sensitivity to analyze real brine pool samples. Unlike ICP and AA, this approach does not require sample preparation or dilution, and samples can be analyzed directly from the brine pools during different stages of the purification process. Moreover, the NMR concentration measurements were shown to be stable over many days, which promises increased reliability and reduced expense and inconvenience associated with day-to-day recalibration. It was also revealed that there is minimal matrix effect with the NMR spectroscopic method and excellent correlation with AA results, with most of the values showing differences below $5 \%$. The reported NMR method does not require the use of deuterated solvents and the only consumables needed are the NMR tubes. This makes the NMR method very inexpensive compare to ICP and AA, which require regular maintenance and gases such as acetylene and argon. All these combined factors provide an attractive new method for the quantification of lithium in the mining industry. We are currently exploring additional applications of benchtop qNMR in various industrial settings.

\section{Conflicts of interest}

J. F. A., P. H., G. M. L. and S. D. R. are employed by Nanalysis Corp. 


\section{Acknowledgements}

R. M. and C. G. would like to acknowledge SQM for financial support to explore new initiatives. J. F. A. would like to thank Felipe Verdugo for valuable discussions.

\section{Notes and references}

1 N. Linneen, R. Bhave and D. Woerner, Sep. Purif. Technol., 2019, 214, 168-173.

2 J. K. Rybakowski, ACS Chem. Neurosci., 2014, 5, 413-421.

3 A. Nassar and A. N. Azab, ACS Chem. Neurosci., 2014, 5, 451-458.

4 B. Swain, J. Chem. Technol. Biotechnol., 2016, 91, 25492562.

5 O. Gröger, H. A. Gasteiger and J.-P. Suchsland, J. Electrochem. Soc., 2015, 162, A2605-A2622.

6 B. Dunn, H. Kamath and J. M. Tarascon, Science, 2011, 334, 928-935.

7 A. Battistel, M. S. Palagonia, D. Brogioli, F. La Mantia and R. Trócoli, Adv. Mater., 2020, 32, 1905440.

8 A. M. Haregewoin, A. S. Wotango and B. J. Hwang, Energy Environ. Sci., 2016, 9, 1955-1988.

9 P. K. Choubey, M. S. Kim, R. R. Srivastava, J. C. Lee and J. Y. Lee, Miner. Eng., 2016, 89, 119-137.

10 J. Wang, M. Chen, H. Chen, T. Luo and Z. Xu, Procedia Environ. Sci., 2012, 16, 443-450.

11 J. Kogel, N. Trivedi, J. Barker and S. Krukowski, Industrial Minerals and Rocks: Commodities, Markets and Uses. Society for Mining, Metallurgy and Exploration, Society for Mining, Metallurgy, and Exploration, 7th edn, 2006.

12 P. Meshram, B. D. Pandey and T. R. Mankhand, Hydrometallurgy, 2014, 150, 192-208.

13 V. K. Silvana, F. R. Horacio and O. M. Agustina, World J. Res. Rev., 2016, 3, 66-70.

14 J. W. An, D. J. Kang, K. T. Tran, M. J. Kim, T. Lim and T. Tran, Hydrometallurgy, 2012, 117-118, 64-70.

15 B. Swain, Sep. Purif. Technol., 2017, 172, 388-403.

16 Y. Morishige and A. Kimura, SEI Tech. Rev., 2008, 106-111.

17 X. Wen, P. Ma, G. Zhu and Z. Wu, Rare Met., 2006, 25, 309315.

18 A. Sapkota, M. Krachler, C. Scholz, A. K. Cheburkin and W. Shotyk, Anal. Chim. Acta, 2005, 540, 247-256.

19 B. Baraj, L. F. H. Niencheski, R. D. Trapaga, R. G. França, V. Cocoli and D. Robinson, Fresenius' J. Anal. Chem., 1999, 364, 678-681.

20 D. Quaglio, S. Corradi, S. Erazo, V. Vergine, S. Berardozzi, F. Sciubba, F. Cappiello, M. E. Crestoni, F. Ascenzioni, F. Imperi, F. Delle Monache, M. Mori, M. R. Loffredo, F. Ghirga, B. Casciaro, B. Botta and M. L. Mangoni, ACS Med. Chem. Lett., 2020, 11, 760-765.

21 M. O. Marcarino, M. M. Zanardi, S. Cicetti and A. M. Sarotti, Acc. Chem. Res., 2020, 53, 1922-1932.

22 J. J. J. Van Der Hooft, R. C. H. De Vos, V. Mihaleva, R. J. Bino, L. Ridder, N. De Roo, D. M. Jacobs, J. P. M. Van
Duynhoven and J. Vervoort, Anal. Chem., 2012, 84, 72637271.

23 A. V. Buevich and M. E. Elyashberg, J. Nat. Prod., 2016, 79, 3105-3116.

24 D. K. Menyhárd, G. Pálfy, Z. Orgován, I. Vida, G. M. Keserü and A. Perczel, Chem. Sci., 2020, 11, 9272-9289.

25 V.-T. Vu, M.-T. Nguyen, W.-L. Wang, B.-N. Nguyen, G.-N. Pham, L.-Y. Kong and J.-G. Luo, Org. Biomol. Chem., 2020, 2, 6607-6611.

26 N. E. Jacobsen, NMR Spectroscopy Explained: Simplified Theory, Applications and Examples for Organic Chemistry and Structural Biology, Wiley-Interscience, 2007.

27 G. F. Pauli, S. N. Chen, C. Simmler, D. C. Lankin, T. Gödecke, B. U. Jaki, J. B. Friesen, J. B. McAlpine and J. G. Napolitano, J. Med. Chem., 2014, 57, 9220-9231.

28 L. A. C. Pieters and A. J. Vlietinck, J. Pharm. Biomed. Anal., 1989, 7, 1405-1417.

29 U. Holzgrabe, R. Deubner, C. Schollmayer and B. Waibel, J. Pharm. Biomed. Anal., 2005, 38, 806-812.

30 T. Schoenberger, S. Menges, M. A. Bernstein, M. Pérez, F. Seoane, S. Sýkora and C. Cobas, Anal. Chem., 2016, 88, 3836-3843.

31 G. F. Pauli, B. U. Jaki and D. C. Lankin, J. Nat. Prod., 2007, 70, 589-595.

32 P. Giraudeau, Magn. Reson. Chem., 2017, 55, 61-69.

33 E. Hafer, U. Holzgrabe, K. Kraus, K. Adams, J. M. Hook and B. Diehl, Magn. Reson. Chem., 2020, 58, 653-665.

34 W. von Philipsborn, Pure Appl. Chem., 1986, 58, 513528.

35 J. T. Urban, Nuclear Magnetic Resonance Studies of Quadrupolar Nuclei and Dipolar Field Effects, University of California, Berkeley, 1997.

36 C. Gerardin, M. Haouas, C. Lorentz and F. Taulelle, Magn. Reson. Chem., 2000, 38, 429-435.

37 H. Maki, G. Sakata and M. Mizuhata, Analyst, 2017, 142, 1790-1799.

38 L. M. Ravaglia, D. dos S. Freitas, T. G. Ricci, C. E. D. Nazario and G. B. Alcantara, Magn. Reson. Chem., 2020, 58, 186-190.

39 L. M. Aguilera-Sáez, J. R. Belmonte-Sánchez, R. RomeroGonzález, J. L. Martínez Vidal, F. J. Arrebola, A. Garrido Frenich and I. Fernández, Analyst, 2018, 143, 47074714.

40 L. Sassu, S. Puligheddu, C. Puligheddu and S. Palomba, Magn. Reson. Chem., 2020, 58, 1222-1233.

41 J. C. Edwards, Magn. Reson. Chem., 2016, 54, 492-493.

42 P. Sagmeister, J. Poms, J. D. Williams and C. O. Kappe, React. Chem. Eng., 2020, 5, 677-684.

43 W. G. Lee, M. T. Zell, T. Ouchi and M. J. Milton, Magn. Reson. Chem., 2020, 58, 1193-1202.

44 S. Yamada, K. Ito, A. Kurotani, Y. Yamada, E. Chikayama and J. Kikuchi, ACS Omega, 2019, 4, 3361-3369.

45 K. Meyer, S. Kern, N. Zientek, G. Guthausen and M. Maiwald, Trends Anal. Chem., 2016, 83, 39-52.

46 F. Dalitz, M. Cudaj, M. Maiwald and G. Guthausen, Prog. Nucl. Magn. Reson. Spectrosc., 2012, 60, 52-70. 
47 M. H. M. Killner, E. Danieli, F. Casanova, J. J. R. Rohwedder and B. Blümich, Fuel, 2017, 203, 171178.

48 M. Grootveld, B. Percival, M. Gibson, Y. Osman, M. Edgar, M. Molinari, M. L. Mather, F. Casanova and P. B. Wilson, Anal. Chim. Acta, 2019, 1067, 11-30.

49 S. Berger and S. Braun, 200 and more NMR experiments: a practical course, Wiley-VCH, 2004.

50 H. J. Reich, D. P. Green and N. H. Phillips, J. Am. Chem. Soc., 1989, 111, 3444-3445.

51 H. J. Reich and K. J. Kulicke, J. Am. Chem. Soc., 1996, 118, 273-274.

52 L. M. Jackman, L. M. Scarmoutzos and C. W. Debrosse, J. Am. Chem. Soc., 1987, 109, 5355-5361.

53 J. C. Handman, J. Chem. Phys., 1962, 36, 10001015.

54 G. V. Karpov, Chem. Phys. Lett., 2005, 402, 300-305.

55 G. Maniara, K. Rajamoorthi, S. Rajan and G. W. Stockton, Anal. Chem., 1998, 70, 4921-4928.
56 T. Schonberger, Y. B. Monakhova, D. W. Lachenmeier and T. Kuballa, EUROLABS Technical Report No. 01/2014 May 2014, 2014.

57 J. C. Miller and J. N. Miller, Analyst, 1988, 113, 1351-1356.

58 J. N. Miller, Analyst, 1991, 116, 3-14.

59 S. K. Bharti and R. Roy, TrAC, Trends Anal. Chem., 2012, 35, $5-26$.

60 O. Beckonert, H. C. Keun, T. M. D. Ebbels, J. Bundy, E. Holmes, J. C. Lindon and J. K. Nicholson, Nat. Protoc., 2007, 2, 2692-2703.

61 J. Mispelter, M. Lupu and A. Briguet, NMR Probeheads for Biophysical and Biomedical Experiments, Imperial College Press, 2nd edn, 2015.

62 D. Harvey, Analytical Chemisty 2.1, Open Education Resource (OER) LibreTexts Project.

63 D. L. Olson, T. L. Peck, R. L. Magin, J. V. Sweedler and A. G. Webb, Science, 1995, 270, 1967-1970.

64 J. H. Lee, Y. Okuno and S. Cavagnero, J. Magn. Reson., 2014, 241, 18-31. 